Research Paper

\title{
Identiiication of Mannich Base as a Novel Inhibitor of Mycobacterium Tu- berculosis Isocitrate by High-Throughput Screening
}

\author{
Lei Ji ${ }^{1}$, Quanxin Long ${ }^{1}$, Dacheng Yang ${ }^{2}$, Jianping Xie ${ }^{1 凶}$
}

1. Institute of Modern Biopharmaceuticals, State Key Laboratory Breeding Base of Eco-Enviroment and Bio-Resource of the Three Gorges Area, School of Life Sciences, Southwest University, Beibei, Chongqing 400715, China;

2. School of Chemistry and Chemical Engineering, Southwest University, Beibei, Chongqing 400715, China.

$\triangle$ Corresponding author: Tel: 86-23-68367108; Fax: 86-23-68367108; Email: jianpingxiefudan@gmail.com

( ) Ivyspring International Publisher. This is an open-access article distributed under the terms of the Creative Commons License (http://creativecommons.org/ licenses/by-nc-nd/3.0/). Reproduction is permitted for personal, noncommercial use, provided that the article is in whole, unmodified, and properly cited.

Received: 2011.01.16; Accepted: 2011.03.31; Published: 2011.04.07

\begin{abstract}
Mycobacterium tuberculosis (MTB) remains one of the most significant human pathogens since its discovery in I882. An estimated I.5 million people died from tubercle bacillus (TB) in 2006, and globally, there were an estimated 9.27 million incident cases of TB in 2007. Glyoxylate bypass pathway occurs in a wide range of pathogens and plays a key role in the pathogenesis of Mycobacterium tuberculosis. Isocitrate lyase (ICL) can catalyses the first step of this pathway, and reversibly cleaves isocitrate into succinate and glyoxylate. So, ICL may represent a good drug target for the treatment of tuberculosis. ICL was cloned, expressed, and purified, and a high-throughput screen (HTS) developed to screen active molecule from a mannich base compounds library for inhibition of ICL. This assay had signal to noise $(\mathrm{S} / \mathrm{N})$ of 650.6990 and Z' factor of $0.814 \mathrm{I}$, indicating that the assay was suitable for HTS. Screening of a collection of 124 mannich base compounds resulted in the identification of one mannich base compound, which has a significant inhibitory activity. So, a new family of compound was first reported to inhibit the activity of Mycobacterium tuberculosis ICL. This family of compound might offer new avenue to explore better anti-tuberculosis and fungi drugs.
\end{abstract}

Key words: Isocitrate Lyase, Mycobacterium tuberculosis, Drug Target, High-Throughput Screening, mannich bases.

\section{Introduction}

Isocitrate lyase (ICL; EC 4.1.3.1) catalyses the first step of the glyoxylate bypass pathway, which reversibly catalysis isocitrate into succinate and glyoxylate. It is the key enzyme in the glyoxylate bypass pathway [1]. Glyoxylate shunt was reported to be pivotal for microbes to survive and thrive on the fatty acid and two-carbon compound as sole carbon source [2].

ICL existed extensively in organisms such as bacteria, nematodes, fungi and plants [3]. No human being homologs have been documented [3]. This made ICL a promising target for broad spectrum antibiotics. ICL is essential for Mycobacterium tuberculosis growth in activated macrophages and persistence in macrophages and mice [4], and virulence factors of Candida albicans, Rhodococcus equi [5-7].

ICL was intensively pursued as drug target to combat tuberculosis. Tuberculosis was once held at bay by the introduction of antibiotics and there was a widespread optimism that it is just a matter of time to eradicate them. However, several factors, including the emergence of drug resistance, multi-drug resistance and even extensive resistance, co-infection with HIV and poor compliance of patients largely due to the lengthy treatment regimen, result in the re-establishment of tuberculosis as a major scourge of 
public health. And this once optimism was relentlessly pulverized. Intense investigations on ICL inhibitor have revealed variety of drug leads promising to proceed into next stage[8]. Many have put on a premium on ICL as a priority target,such as WHO (World Health Organization) [9], GSK and Rockefeller University[10]. ICL expression was reported to be highly spatiotemporal and conventionalscreening might miss some promising leads [11].

B-amino ketones are the key intermediates for the synthesis of lots of drugs and natural products, and are also important bioactive substances [12], with function of anti-inflammatory [13, 14], anti-cancer [15-18], anti-bacterial [18, 19], anti-virus, sedation, analgesia, hypotension, edema suppression and anti-coagulation. more diverse activities were reported, such as: anti-androgen[20], insulin sensitizer, excited peroxisome proliferator-activated receptors (PPARs), inhibit cholesterol acyltransferase (ACAT), and promote high-density lipoprotein receptor (SRBI) expression and reverse tumor multi-drug resistance, such as pharmacological activity, can be used as the prevention and treatment of insulin resistance-related diseases, diabetes, obesity, atherosclerosis, fatty liver, hyperlipidemia, inflammation, tumor diseases, such as multi-drug resistance of the drug/precursor material [21-24]. Our working hypothesis is these compounds might be active against ICL.

A previously proved high-throughput screening model for ICL inhibitors in our lab [25] was employed to screen new ICL inhibitors from the mannich base compounds library. Compound Ydcm67 (Fig.1) demonstrated a strong inhibitory activity to ICL.

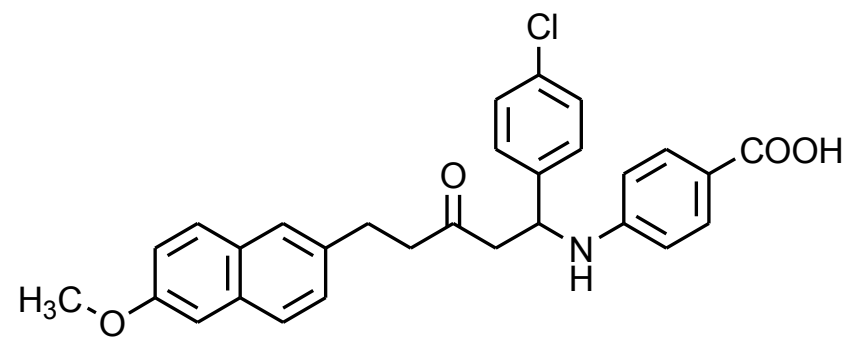

Fig.I Structure of compound Ydcm67

\section{MATERIALS AND METHODS}

\section{Materials}

Mycobacterium tuberculosis $\mathrm{H} 37 \mathrm{Rv}$ was purchased from Chongqing Pulmonary Hospital, China; Escherichia coli DH5a, E. coli DE3 (BL21) and plasmid pET-28a (+) were employed; Pfu DNA Polymerase, DNA marker were purchased from Tiangen Biotech
(Beijing) Co.,Ltd; DNA purification kit was purchased from SBS Genetech Co., Ltd; BamHI, HindIII, T4 DNA ligase, and dNTP were purchased from Takara; Ni-Sepharose and ÄKTA prime were from Amersham Biosciences. Isocitrate and itaconic anhydrate were obtained from Sigma-Aldrich. The mannich base compounds library was constructed by Pro. Dacheng Yang's lab, School of Chemistry and Chemical Engineering, Southwest University, China. The 96-well plate for UV assay was purchased from Greiner. Absorbance was read at $324 \mathrm{~nm}$ on SpectraMaxs 190 (Molecular Devices, Sunnyvale, CA).

\section{Cloning and Expression of Recombinant ICL}

The genomic DNA was prepared using $\mathrm{CTAB}[26]$. A 1.3-kb DNA fragment containing the aceA gene was amplified by nested PCR using the following four oligonucleotide primers: OutF: $5^{\prime}$ CGC CTC GCT GTT GAA TCT GT 3' and OutR: 5' CGC TCA CTG TTC CTC CTC AAA T $3^{\prime}$ for first PCR; ICLF: 5' TA GGA TCC ATG TCT GTC GTC GGC AC $3^{\prime}$ and ICLR: 5' TCA AAG CTT CTA GTG GAA CTG GCC CTC T 3' (restriction sites are indicated with single underlines) for second PCR. The amplified DNA was digested using BamHI and HindIII, and ligated into pET-28a (+), then the recombinant plasmid pET28a-ICL was transformed into E. coli DH5a. The nucleotide sequence was done on an ABI 3730 sequencer. For over-expression, E. coli DE3 (BL21) carrying the recombinant plasmid pET28a-ICL was grown to an exponential phase at $37^{\circ} \mathrm{C}$ in $\mathrm{Lu}-$ ria-Bertani (LB) medium [27] plus kanamycin (50 $\mathrm{\mu g}$ $\mathrm{ml}^{-1}$ ). Expression of ICL was induced by $0.1 \mathrm{mM}$ IPTG for $4 \mathrm{~h}$ at $30^{\circ} \mathrm{C}$. Cells were harvested by centrifugation at $4^{\circ} \mathrm{C}$, and cell pellets were stored at $-20^{\circ} \mathrm{C}$.

\section{Purification of ICL}

Using Buffer A $\left(50 \mathrm{mM} \mathrm{NaH}_{2} \mathrm{PO} 4,300 \mathrm{mM} \mathrm{NaCl}\right.$, $10 \mathrm{mM}$ imidazole, $\mathrm{pH} 8.0$ ) as the lysis buffer, and the lysate was centrifuged at $13,000 \mathrm{~g}$ for $30 \mathrm{~min}$ at $4^{\circ} \mathrm{C}$. The cell extract was applied to Ni-sepharose (Amersham Biosciences) and fractions with ICL activity were collected and stored at $4^{\circ} \mathrm{C}$ for 2 months with no loss of activity.

\section{Enzyme Assay}

Isocitrate lyase activity was determined at $37^{\circ} \mathrm{C}$ by measuring the formation of glyoxylate-phenylhydrazone in the presence of phenylhydrazine and isocitrate lyase at $324 \mathrm{~nm}$ based on the method described [28]. The reaction buffer include 50 $\mathrm{mM}$ potassium phosphate, $4 \mathrm{mM} \mathrm{MgCl}_{2}, 4 \mathrm{mM}$ Phenylhydrazine $\mathrm{HCl}, 12 \mathrm{mM}$ Cysteine $\mathrm{HCl}, \mathrm{pH} 7.0$, and it was kept on ice until use. The mixture of $188 \mu \mathrm{l}$ reaction buffer and $2 \mu \mathrm{l}$ recombinant ICL solution was 
incubated at $37^{\circ} \mathrm{C}$ for $30 \mathrm{~min}$, and the change of absorbance at $324 \mathrm{~nm}$ was measured after the addition of $10 \mu \mathrm{l}$ isocitrate. The $\mathrm{Km}$ and Vmax was gained using the Hanes-Woolf plot [29], with the slope $=1 / \mathrm{Vmax}$ and the intercept on the $\mathrm{x}$ axis $=-\mathrm{Km}$.

\section{Optimization of Enzyme Assay in 96-Well Plate}

The mixture of reaction buffer and different unit enzyme was incubated at $37^{\circ} \mathrm{C}$ for $30 \mathrm{~min}$, and absorbance at $324 \mathrm{~nm}$ was read as control values. Then isocitrate was added, and the plate was incubated at $37^{\circ} \mathrm{C}$. The absorbance at $324 \mathrm{~nm}$ was read as experimental values every 10 min for 5 times.

\section{Preparation of Mannich Base Solution}

The mannich base compounds were dissolved in DMSO to obtain final concentrations of $1.0 \mathrm{mg} / \mathrm{ml}$, and stored at $-20^{\circ} \mathrm{C}$.

\section{High-Throughput Screening}

The test mannich base solutions were diluted on the mother plate $(1.0 \mathrm{mg} / \mathrm{ml}$ in $100 \%$ DMSO), and 10 $\mu l$ of each extract solution was added into each well (equivalent to a final concentration of $0.05 \mathrm{mg} / \mathrm{ml}$ ) of a 96-well plate. The A1, B1, and C1 represent the background, negative control and positive control ( $0.05 \mathrm{M}$ oxalic acid) respectively. Subsequently, $178 \mu \mathrm{l}$ reaction buffer, $10 \mu \mathrm{l}$ compound solution, $2 \mu \mathrm{l}$ recombinant protein ICL solution, and $10 \mu \mathrm{l}$ isocitrate solution $(0.04 \mathrm{M})$ was added to each well, and the absorbance was measured as described above. The inhibition $>50 \%$ of extracts were picked up for the following screen to reconfirm the inhibition, and the screen assay was done in duplicate. To determine the $\mathrm{IC}_{50}$, five concentrations were used.

\section{Data Analysis}

The activity detection of ICL was based on the absorbance at $324 \mathrm{~nm}$, and the activity was calculated by the change of absorbance (experimental values control values). The signal to noise $(\mathrm{S} / \mathrm{N})$ and screening window coefficients ( $Z^{\prime}$ factor) were calculated as described by Zhang, et al[30] to evaluate the suitability of the model for screening. Data that were detected from eight wells have been used to calculate the $\mathrm{S} / \mathrm{N}$ and $\mathrm{Z}^{\prime}$ factor.

\section{RESULTS}

\section{Screening and Identification of Recombinant Plasmid}

Recombinant plasmid was isolated from clones growing on LB medium supplement with kanamycin $\left(50 \mu \mathrm{g} \mathrm{ml}^{-1}\right)$, and found to contain an intact copy of the 1.3-kb DNA by two enzymes digestion (Fig.2). The sequence result showed that no mutations were dis- covered, confirming the construction of recombinant plasmid pET28a-ICL.

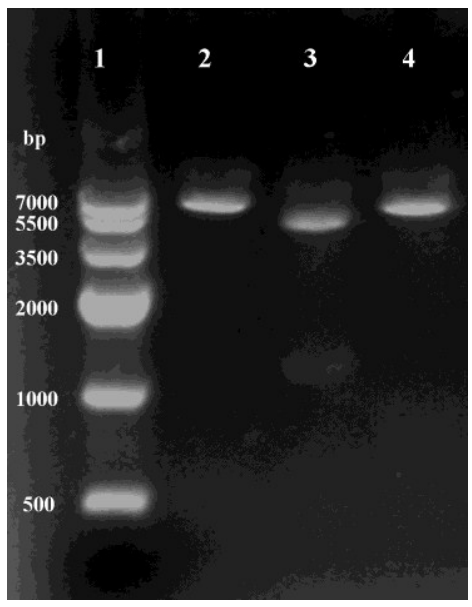

Fig.2 Using restriction enzymes digest recombinant plasmid pET28a-ICL. Lane I: Marker IV; Lane 2 and 4: BamHI and Hindlll single digestion; Lane 3: BamHI and HindllI double digestion.

\section{Overexpression of Recombinant ICL}

Recombinant ICL was overexpressed in E. coli DE3 (BL21). Using SDS-PAGE analysis of recombinant ICL in the inclusion body and supernatant (Fig.3A). Than using ÄKTA prime (Amersham Biosciences, USA) purified recombinant ICL protein (Fig.3B).

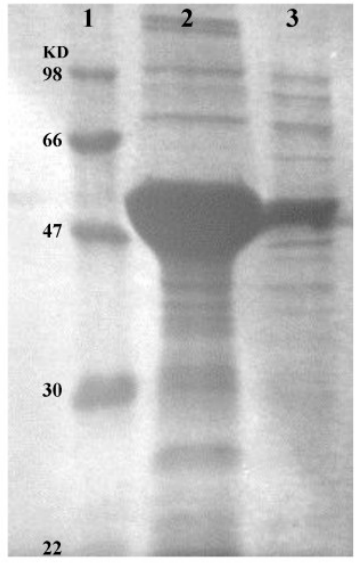

A

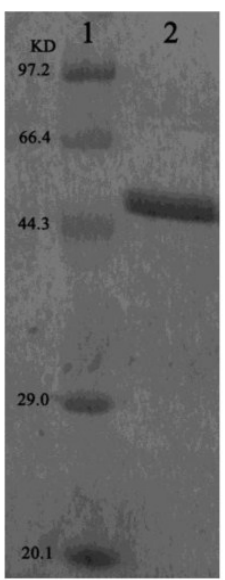

B
Fig.3 A: SDS-PAGE analysis of recombinant ICL in the inclusion body and supernatant. Lane I: Protein marker; Lane 2-3: Precipitate and supernatant of sonicated broken E.coli DE3 (BL2I) transformed with $\mathrm{pET} 28 \mathrm{a}-\mathrm{ICL}$, respectively. B: SDS-PAGE analysis of recombinant ICL that purified. Lane I: Protein marker; Lane 2: Purified protein. 


\section{Enzyme Assay and Optimization}

The recombinant enzyme activity was 21,500 $\mathrm{U} / \mathrm{L}$. Using the Hanes-Woolf plot, the Km and Vmax were determined to be $219 \mathrm{mM}$ and 3.127 $\mathrm{mM} / \mathrm{min} / \mathrm{mg}$, respectively. The results showed that the production of glyoxylate-phenylhydrazone was linear with the time of incubation up to 20 min (Fig.4) and with the amount of protein in the assay at $2 \mathrm{mM}$ concentration of isocitrate. Therefore, the optimized condition of ICL for assay was fixed at $2 \mu$ l enzyme solution (approximately equal to $215 \mathrm{U} / \mathrm{L}$ ) in each well, and an incubation time of $20 \mathrm{~min}$ at $37^{\circ} \mathrm{C}$ was used.

The $\mathrm{IC}_{50}$ value of oxalic acid to ICL was $0.013 \mathrm{M}$ determined over a range of inhibitors' final concentrations $(0.005 \mathrm{M}-0.05 \mathrm{M})$ under the optimized conditions (Fig.5).

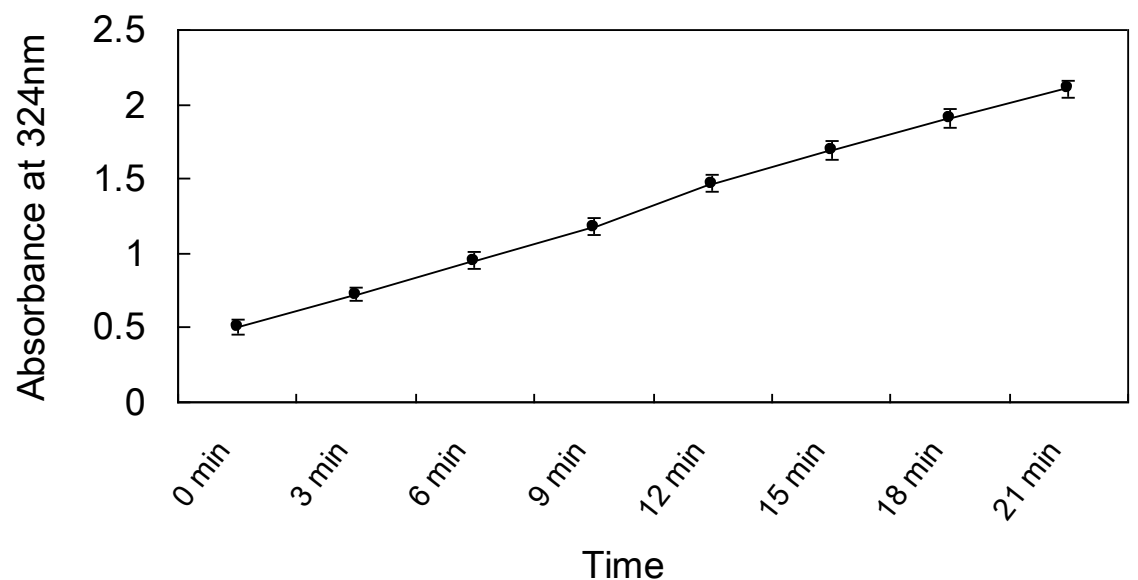

Fig. 4 Isocitrate lyase activity as determined by the assay as a function of time.

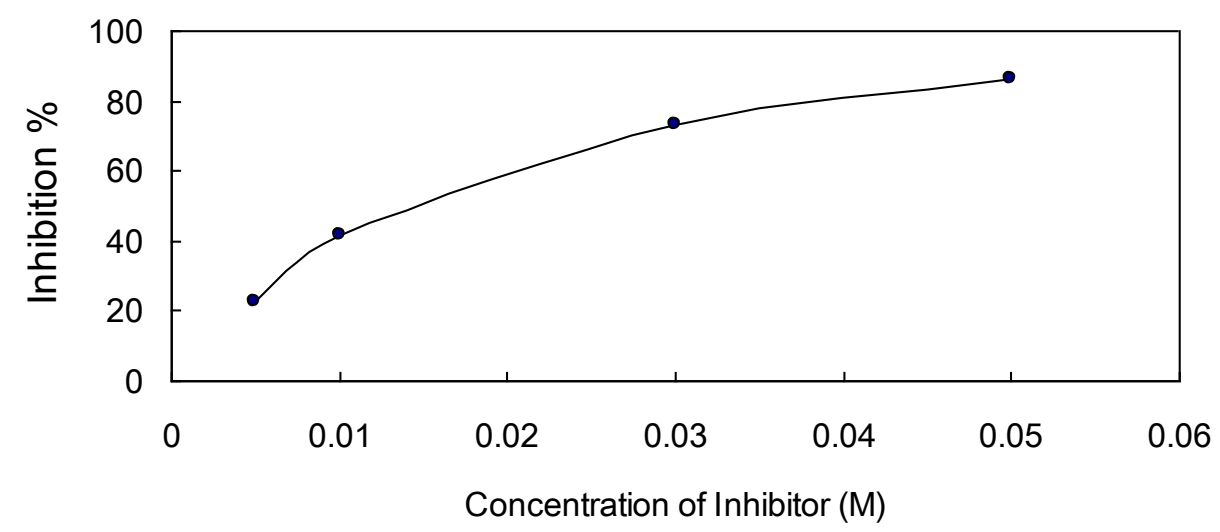

Fig.5 Dose response curves for oxalic acid which inhibits ICL activity 
As described in Materials and Methods, the signal to noise $(\mathrm{S} / \mathrm{N})$ and $\mathrm{Z}^{\prime}$ factor was calculated from the control wells of screening plates to determine the suitability of the assay for high throughput screening. The $Z^{\prime}$ factor reflects the dynamic range as well as the variation of the assay and is a useful tool for assay comparisons and assay quality determinations[30]. The assay exhibits $\mathrm{S} / \mathrm{N}$ of 650.6990 and $\mathrm{Z}^{\prime}$ factor of 0.8141 (Table 1).

Table I. ICL activity assay parameters

\begin{tabular}{ll}
\hline & Value \\
\hline $\mathrm{M}_{\text {Signal }}{ }^{\text {a }}$ & 1.0211 \\
$\mathrm{M}_{\text {Background }}{ }^{\mathrm{b}}$ & 0.0088 \\
$\mathrm{SD}_{\text {Background }}{ }^{\mathrm{c}}$ & 0.0016 \\
Signal-to-noise(S/N) d $^{\mathrm{Z}}$ Z factor $^{\mathrm{e}}$ & 650.6990 \\
\hline
\end{tabular}

a: $\mathrm{M}_{\text {signal, }}$ mean of signal

b: $\mathrm{M}_{\text {Background, }}$ mean of background

c: $\mathrm{SD}_{\text {Background, standard deviation of the background }}$

$\mathrm{d}$ and e[30]: the $\mathrm{S} / \mathrm{N}$ and $\mathrm{Z}$ factor were calculated by the equations: ( $\left.\mathrm{M}_{\text {Signal- }} \mathrm{M}_{\text {Background }}\right) / \mathrm{SD}_{\text {Background }} 1-\left[(3 \times \mathrm{SD}\right.$ Positive Control $)+\left(3 \times \mathrm{SD}_{\text {Nega- }}\right.$ tive Control)/(mean positive control-mean negative control)], respectively.

\section{High-Throughput Screening}

In this assay, 124 mannich base compounds were tested. All compounds were evaluated in the assay at a final concentration of $0.05 \mathrm{mg} / \mathrm{ml}$. Inhibition of more than $50 \%$ was defined as a hit. We found Ydcm67 has a significant inhibitory activity (Table 2).

Table 2. Potency of oxalic acid and Ydcm67 against Mycobacterium tuberculosis ICL activity using the colorimetric assay

\begin{tabular}{ll}
\hline & $\mathrm{OD}_{324}$ \\
\hline $\mathrm{M}_{\text {Background }}{ }^{\text {a }}$ & 0.0088 \\
$\mathrm{M}_{\text {Negative Control }}{ }^{\mathrm{b}}$ & 1.0211 \\
$\mathrm{M}_{\text {Positive Control }}{ }^{\mathrm{c}}$ & 0.0538 \\
$\mathrm{M}_{\text {Sample }^{\mathrm{d}}}{ }^{\mathrm{IR}}$ Positive Control $^{\mathrm{e}}$ & 0.4400 \\
$\mathrm{IR}_{\text {Sample }}{ }^{\mathrm{f}}$ & $95.55 \%$ \\
\hline
\end{tabular}

a: $\mathrm{M}_{\text {Background, mean of background }}$

b: $\mathrm{M}_{\text {Negative Control, no inhibitor }}$

c: $\mathrm{M}$ Positive Control, mean of positive control, using $0.05 \mathrm{M}$ oxalic acid solution as positive control

$\mathrm{d}$ : M Sample , mean of sample, using $0.05 \mathrm{mg} / \mathrm{ml}$ Ydcm67 solution

e: IR Positive Control, percent inhibition of oxalic acid: ( $M_{\text {Negative Control - }}$ M Positive Control) $/\left(M_{\text {Negative Control - }} M_{\text {Background }}\right){ }^{*} 100 \%$

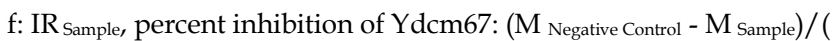
$M_{\text {Negative Control }-M}$ Background) $* 100 \%$

The $\mathrm{IC}_{50}$ value of $\mathrm{Ydcm} 67$ to ICL was 0.0535 $\mathrm{mg} / \mathrm{ml}$ determined over a range of inhibitors' final concentrations $(0.0063 \mathrm{mg} / \mathrm{ml}-0.05 \mathrm{mg} / \mathrm{ml})$ under the optimized conditions (Fig.6).

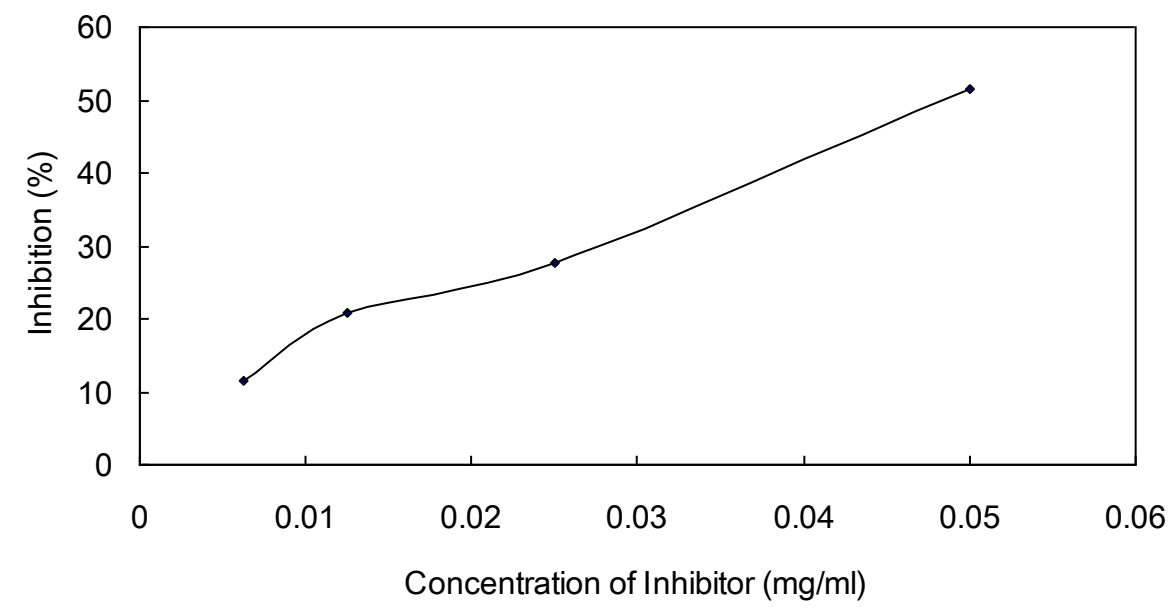

Fig.6 Dose response curves for $Y d c m 67$ which inhibits ICL activity 


\section{DISCUSSION}

To accommodate the assay described to HTS, the optimization of the assay was performed. The incubation time was changed to $30 \mathrm{~min}$ to make full interaction between enzyme and inhibitors, and the changeable values of the absorbance at $324 \mathrm{~nm}$ in 20 min was used to represent the activity of the ICL. Additionally, $2 \mathrm{mM}$ isocitrate and $0.043 \mathrm{U}$ ICL at a final concentration were used in the assay. 124 mannich bases were screened in this assay, and one of them, Ydcm67, exhibited the inhibition of ICL activity, the $\mathrm{IC}_{50}$ value of $Y \mathrm{dcm} 67$ to ICL was $0.0535 \mathrm{mg} / \mathrm{ml}$, and resulting in a total hit rate of $0.81 \%$. Typically, $\mathrm{Z}^{\prime}$ factor $>0.5$ and $S / N>10$ are considered favorable for high throughput screening. Our assay exhibiting S/N of 650.6990 and $Z^{\prime}$ factor of 0.8141 and the reproducibility of positive compounds indicates that it is suitable for high-throughput screening.

Simulated 3D structure of Ycdm67 (Fig.7A) generated via ChemSketch demonstrates that this molecule might function by wedging in the active site of ICL (Fig.7B).

This is the first report that a high-throughput screening assay was developed to screen the mannich base, and one hit is active against ICL. However, in vivo data are needed to evaluate the compound's efficacy and provide structure-activity relationship information.

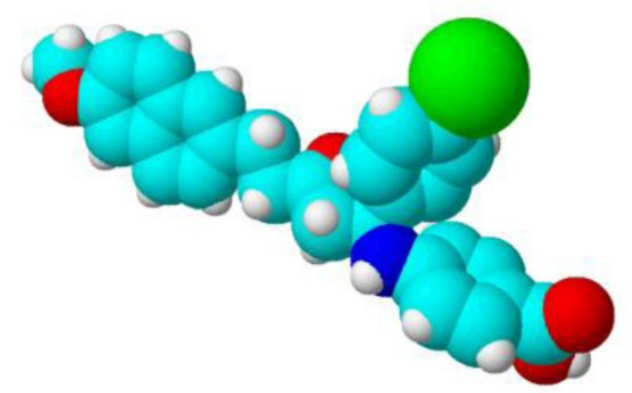

A

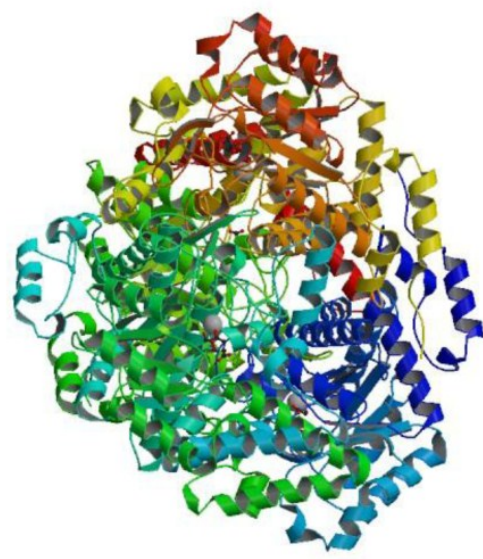

B

Fig.7 A: The 3D structure of Ydcm67 (White: H; Lightcyan: C; Red: O; Mazarine: N; Green:Cl). B: The crystal structure of isocitrate lyase from Mycobacterium tuberculosis (http://www.rcsb.org/pdb/explore/images.do?structureld=I F8I).

\section{Acknowledgements}

This work was supported by the National Key Infectious Disease Project (Grant Nos. 2008ZX10003-006); Excellent PhD Thesis Fellowship of Southwest University (Grant Nos. kb2009010, ky2009009 and kb2010017); Fundamental Research Funds for the Central Universities (Grant No. XDJK2009A003); National Natural Science Foundation (Grant No. 81071316) and Natural Science Foundation Project of CQ CSTC (Grant No. CSTC, 2010BB5002).

\section{Conflict of Interests}

The authors have declared that no conflict of interest exists.

\section{References}

1. Campbell J.J, Smith R.A, and Eagles B.A. A deviation from the conventional tricarboxylic acid cycle in Pseudomonas aeruginosa. Biochim Biophys Acta. 1953; 11: 594.

2. Kornberg H.L and Krebs H.A. Synthesis of cell constituents from C2-units by a modified tricarboxylic acid cycle. Nature. 1957; 179: 988-91.

3. Britton K, Langridge S, Baker P.J, et al. The crystal structure and active site location of isocitrate lyase from the fungus Aspergillus nidulans. Structure. 2000; 8: 349-62.

4. McKinney J.D, Honer zu Bentrup K., Munoz-Elias E.J, et al. Persistence of Mycobacterium tuberculosis in macrophages and mice requires the glyoxylate shunt enzyme isocitrate lyase. Nature. 2000; 406: 735-8.

5. Kelly B.G, Wall D.M, Boland C.A, et al. Isocitrate lyase of the facultative intracellular pathogen Rhodococcus equi. Microbiology. 2002; 148: 793-8.

6. Lorenz M.C and Fink G.R. The glyoxylate cycle is required for fungal virulence. Nature. 2001; 412: 83-6. 
7. Lorenz M.C and Fink G.R. Life and death in a macrophage: role of the glyoxylate cycle in virulence. Eukaryot Cell. 2002; 1: 657-62.

8. Floyd K, Blanc L, Raviglione M, et al. Resources required for global tuberculosis control. Science. 2002; 295: 2040-1.

9. WHO. Past, present and future of TB control. Geneva: WHO. 2005.

10. Sharma V, Sharma S, et al. Structure of isocitrate lyase, a persistence factor of Mycobacterium tuberculosis. Nat Struct Biol. 2000; 7: 663-8.

11. McKinney J.D. In vivo veritas: the search for TB drug targets goes live. Nat Med. 2000; 6: 1330-3.

12. Tramontini $\mathrm{M}$ and Angiolini L. Further advances in the chemistry of mannich bases. Tetrahedron. 1990; 46: 1791-1837.

13. Dong J, Xu L, and Ji Z. Synthesis and antiinflammatory activity of 2-substituted cyclo-pentanone or 2-cyclopentenone Mannich bases from aromatic amines. Chin J Med Chem. 1998; 8: 5-9.

14. Chen $H$, Jing $Y$, Ji Z, et al. Synthesis and anti-inflammatory and anticancer activities of 2-(E)- (un)substituted benzylidene cyclopentanones and their Mannich base hydro chlorides. Acta Pharm Sin. 1991; 26: 183-192.

15. El-Subbagh H.I, Abu-Zaid S.M, Mahran M.A, et al. Synthesis and biological evaluation of certain alpha,beta-unsaturated ketones and their corresponding fused pyridines as antiviral and cytotoxic agents. J Med Chem. 2000; 43: 2915-21.

16. Yang D, Fan L, Liu H, et al. A class of compounds that has the Mannich base stucture and its applications in the preparation of the treatment and/or prevention of leukemia drug. Chinese patent application No.200710092667.9. 2007.

17. Ma Y, Yin L, Liu Y, et al. Synthesis and antitumor activities of 2-(E)-(4-cyclo -pentyloxy -3-methyl-benzylidene) cyclopentanone arylamine Mannich bases. Chin J Med Chem. 2006; 16: 144-149.

18. Kocabalkanli A, Ates O, and Otuk G. Synthesis of Mannich bases of some 2,5-disubstituted 4-thiazolidinones and evaluation of their antimicrobial activities. Arch Pharm (Weinheim). 2001; 334: 35-9.

19. Joshi S, Khosla N, Khare D, et al. Synthesis and in vitro study of novel Mannich bases as antibacterial agents. Bioorg Med Chem Lett. 2005; 15: 221-6.

20. Zhou C, Wu G, Feng Y, et al. Discovery and biological characterization of a novel series of androgen receptor modulators. $\mathrm{Br}$ J Pharmacol. 2008; 154: 440-50.

21. Song X, Yan J, Fan L, et al. Synthesis and Preliminary Evaluation of Antidiabetic Activity of 4-(1-Aryl-3-aryl/arylalkyl-3-oxopropylamino)-N-(5-methyl-3-is oxazolyl)benzene Sulfonamide. Chin J Org Chem. 2009; 29: 606-613.

22. Xu J, Yan J, Fan L, et al. Synthesis and a -glucosidase inhibitory activity of N-(1,5-diaryl-3-pentone-1-yl)-4-aminobenzoic acid. Acta Pharm Sin. 2009; 44: 48-55.

23. Yang D, Yan J, Fan L, et al. $\beta$-amino ketone derivatives for antidiabetic activity. Chinese patent application No. 200810237001.2. 2008.

24. Li Q, Yang D, Yan J, et al. A kind of new $\beta$-amino ketone/alcohol derivatives and its use. Chinese patent application No.200810148122.X. 2008

25. Bai B, Xie J, Yan J, et al. A high throughput screening approach to identify isocitrate lyase inhibitors from traditional Chinese medicine sources. Drug Dev Res. 2006; 67: 818-823.

26. Graham F, Hatfull W.R.J. Molecular genetics of mycobacteria. ASM Press. 2000; 316.

27. Sambrook J, Fritsch E.F, and Maniatis T. Molecular cloning: a laboratory manual. Cold Spring Harbor, NY: Cold Spring Harbor Laboratory Press. 1989.

28. Dixon G.H and Kornberg H.L. Proceedings of the Biochemical Society. Biochem J. 1959; 72: 1P-13P.
29. Hanes C.S. Studies on plant amylases: The effect of starch concentration upon the velocity of hydrolysis by the amylase of germinated barley. Biochem J. 1932; 26: 1406-21.

30. Zhang J.H, Chung T.D, and Oldenburg K.R. A Simple Statistical Parameter for Use in Evaluation and Validation of High Throughput Screening Assays. J Biomol Screen. 1999; 4: 67-73. 